\title{
ANALISIS KEKUATAN TARIK HASIL PENGELASAN GESEK LOGAM SIMILAR MONEL
}

\author{
${ }^{(1)}$ Mochamad Bastomi, ${ }^{(2)}$ Muhammad Faisal \\ (1)(2)Program Studi Teknik Mesin, Politeknik Kotabaru \\ Jalan Raya Stagen Km. 9,5 Kotabaru Kalimantan Selatan \\ Email :m.bastomi09@gmail.com,faisal.tychal@gmail.com
}

\begin{abstract}
Abstrak
Penelitian ini membahas tentang analisis perbandingan kekuatan tarik hasil pengelasan gesek logam similar monel dengan raw metal monel tanpa pengelasan. Penelitian dilakukan dengan eksperimen uji tarik pada dua spesimen yang terdiri dari 1 spesimen raw metal monel tanpa pengelasan dan 1 spesimen hasil pengelasan gesek logam similar monel. Pengelasan gesek dilakukan dengan menggunakan mesin bubut yang telah dimodifikasi pada putaran $1600 \mathrm{rpm}$ dan beban gesek sebesar $10 \mathrm{~kg}$. Bentuk spesimen dibubut sesuai standar ASTM A 370-07a dan selanjutnya dilakukan pengujian tarik. Diperoleh hasil tegangan tarik maksimal pada spesimen hasil pengelasan gesek logam similar monel sebesar $406.108 \mathrm{MPa}$, regangan sebesar $5.0 \%$, dan modulus elastisitas sebesar $8.12 \mathrm{GPa}$. Sedangkan tegangan tarik maksimal spesimen logam monel tanpa pengelasan gesek yaitu sebesar $1025.957 \mathrm{MPa}$, regangan sebesar $27.5 \%$, dan modulus elastisitas sebesar $3.73 \mathrm{GPa}$. Proses penyambungan monel dengan pengelasan gesek belum layak untuk digunakan kembali, karena kekuatan tariknya yang kurang dari setengah dari kekuatan tarik logam monel raw metal tanpa pengelasan.
\end{abstract}

Kata kunci: monel, pengelasan gesek, kekuatan tarik

\begin{abstract}
This study discusses the comparative analysis of the tensile strength results of welding of similar monel friction with raw metal monel without welding. The study was conducted with a tensile test experiment on two specimens consisting of 1 raw metal monel specimen without welding and 1 specimen similar to friction metal monel welding. Friction welding is carried out using a lathe that has been modified at 1600 rpm and a friction load of $10 \mathrm{~kg}$. The specimen shape is turned according to ASTM A 370-07a standard and then tensile testing is performed. Obtained the maximum tensile stress results in the specimen results of welding monel similar metal friction of 406,108 $M P a$, strain of $5.0 \%$, and modulus of elasticity of $8.12 \mathrm{GPa}$. While the maximum tensile stress of monel metal specimens without friction welding is 1025,957 MPa, strain is $27.5 \%$, and elastic modulus is $3.73 \mathrm{GPa}$. The process of connecting monel with friction welding is not suitable for reuse, because its tensile strength is less than half of the tensile strength of raw monel metal without welding.
\end{abstract}

Keywords: monel, friction welding, tensile strength 


\section{PENDAHULUAN}

Logam monel banyak digunakan sebagai poros kemudi maupun sebagai poros penerus gaya gerak dari mesin ke baling-baling kapal. Poros yang patah memerlukan perbaikan dengan proses pengelasan.Penyambungan poros dengan pengelasan gesek dapat meminimalisir bergesernya sumbu dari material yang dilas.[6] Penelitian ini bertujuan untuk mengetahui perbandingan kekuatan tarik material logam monel raw metal dengan kekuatan tarik hasil pengelasan gesek logam similar monel.

\section{METODE PENELITIAN}

Adapun penelitian dilakukan dengan metode eksperimen melalui langkahlangkah sebagai berikut:

1. Proses Pengelasan Gesek

a. Material monel yang sudah dipotong sesuai dengan dimensi yang telah ditentukan yaitu panjang $100 \mathrm{~mm}$ dan diameter $12 \mathrm{~mm}$, diperlihatkan pada Gambar 3.

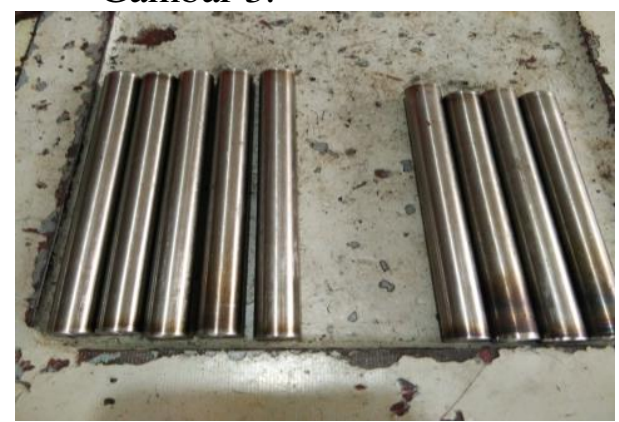

Gambar 3.Spesimen monel sebelum dilas gesek.

(Sumber : Data primer)

b. Persiapan dilakukan proses pengelasan gesek dengan mesin bubut yang sudah di modifikasi.

c. Material monel yang akan dilas, dijepit pada chuck bubut yang berputar dan yang lainnya dijepit pada chuck yang terpasang pada tail stock.

d. Mengatur tuas kecepatan putaran mesin $1600 \mathrm{rpm}$.

e. Sebelum mesin mulai berputar, beban diberikan terlebih dahulu pada kepala lepas mesin bubut yang telah dimodifikasi untuk memberikan gaya penekanan gesekan. Beban yang diberikan adalah $10 \mathrm{~kg}$.

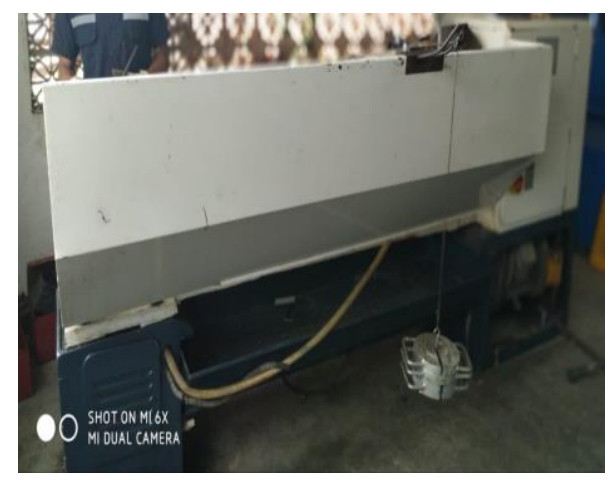

Gambar 4. Pemberian Beban

(Sumber : Data primer)

f. Ketika material telah tersambung, pengereman langsung dilakukan dan mesin dimatikan.

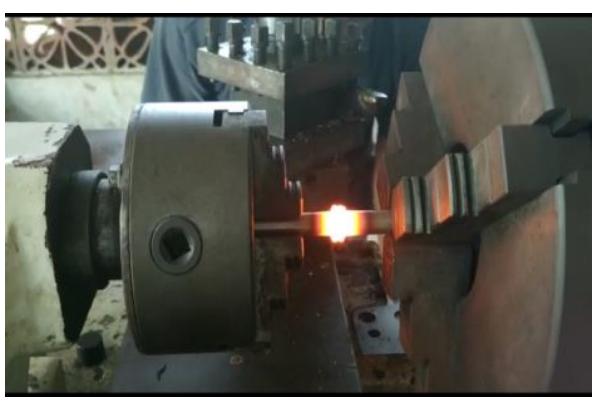

Gambar 5. Material Tersambung (Sumber : Data primer)

g. Gambar 5 menunjukan terjadinya penyambungan logam similar monel dengan proses las gesek. Setelah itu, bahan yang telah selesai di las didinginkan secara alami kemudian dilepaskan dari chuck.

2. Proses Pembuatan Spesimen

Spesimen dibuat dua jenis yang terdiri dari spesimen 1 dari logam raw metal monel tanpa pengelasan gesek dan spesimen 2 dari hasil las gesek logam similar monel. Kedua spesimen dibuat dengan dibubut dengan mesin bubut agar sesuai standar ASTM A 370-07a yang diperlihatkan pada Gambar 6. 


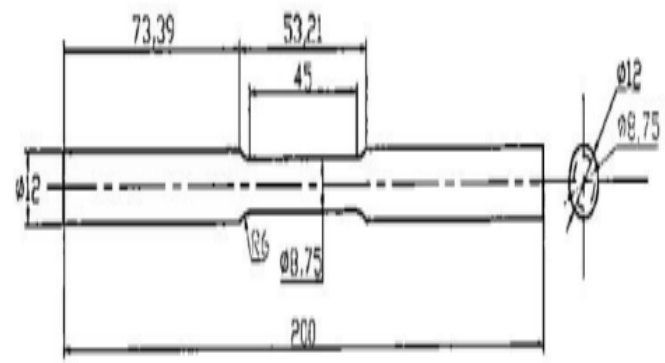

Gambar 6. Spesimen Uji Tarik. [5]

3. Proses Uji Tarik

a. Mempersiapkan spesimen yang dibersihkan terlebih dahulu.

b. Dilakukan pengukuran dimensi, meliputi diameter awal dan panjang awal dengan jangka sorong

c. Spesimen dipasang erat pada alat uji ditunjukan pada Gambar 7.

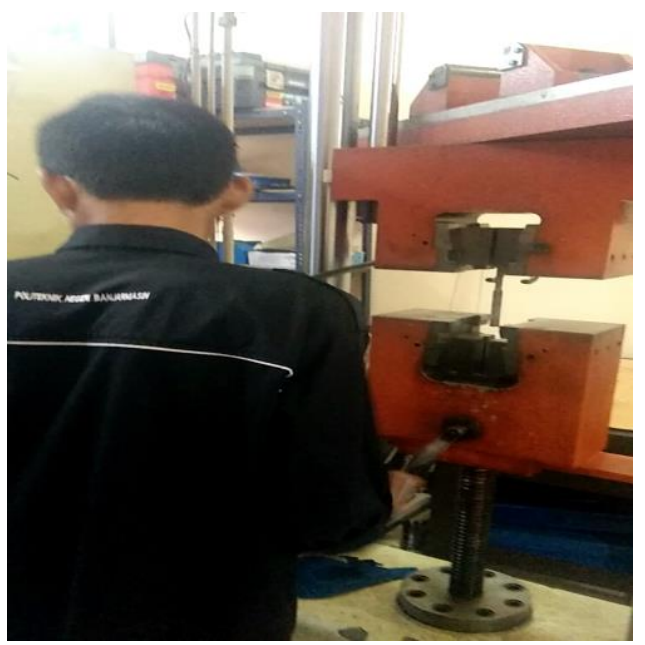

Gambar 7. Pemasangan spesimen pada mesin uji tarik.

(Sumber : Data primer)

Alat uji diatur dan dioperasikan hingga mendapat data gaya tarik titik luluh ( $\left.\mathrm{F}_{\text {yield }}\right)$, gaya tarik maksimal ( $\left.\mathrm{F}_{\text {maks }}\right)$, tegangan tarik titik tuluh $\left(\sigma_{\text {yield }}\right)$ dan tegangan tarik maksimal $\left(\sigma_{\text {maks }}\right)$ dari mesin uji tersebut.

\section{HASIL DAN PEMBAHASAN}

Hasil yang diperoleh dari pengujian tarik pada kedua spesimen terlihat pada Tabel 1.
Tabel 1. Hasil uji tarik spesimen

\begin{tabular}{|c|c|c|}
\hline $\begin{array}{c}\text { Sifat } \\
\text { mekanik }\end{array}$ & $\begin{array}{c}\text { Spesimen } 1 \\
\text { (Raw metal } \\
\text { monel) }\end{array}$ & $\begin{array}{c}\text { Spesimen } 2 \\
\text { (hasil las } \\
\text { gesek } \\
\text { similar } \\
\text { monel) }\end{array}$ \\
\hline $\begin{array}{c}\text { Gaya Tarik } \\
\text { Titik luluh } \\
\text { [N] }\end{array}$ & 54200 & 13000 \\
\hline $\begin{array}{c}\text { Gaya Tarik } \\
\text { Maks [N] }\end{array}$ & 62400 & 24700 \\
\hline $\begin{array}{c}\text { Tegangan } \\
\text { Tarik Titik } \\
\text { Luluh[MPa] }\end{array}$ & 891.136 & 213.741 \\
\hline $\begin{array}{c}\text { Tegangan } \\
\text { Tarik Maks } \\
\text { [MPa] }\end{array}$ & 1025.957 & 406.108 \\
\hline $\begin{array}{c}\text { Regangan } \\
{[\%]}\end{array}$ & 27.5 & 5.0 \\
\hline $\begin{array}{c}\text { Modulus } \\
\text { Elastisitas } \\
{[\mathrm{GPa}]}\end{array}$ & 3.73 & 8.12 \\
\hline
\end{tabular}

(Sumber : Data primer)

Dari hasil pengamatan, pada spesimen 2 , terjadi putus pada sambungan las.

Berdasarkan pengujian yang telah dilakukan, tegangan tarik pada spesimen 2 hasil pengelasan gesek logam similar monel, belum cukup baik dibandingkan dengan spesimen 1, raw metal monel yang tanpa pengelasan gesek. Hasil pengujian yang diperlihatkan pada Tabel 1 menunjukkan tegangan tarik maksimal pada spesimen 2 hasil pengelasan gesek logam similar monel yaitu sebesar 406.108 Mpa, regangan sebesar 5.0\%, dan modulus elastisitas sebesar 8.12 GPa. Sedangkan kekuatan tarik maksimal spesimen 1 monel tanpa pengelasan gesek yaitu sebesar 1025.957 Mpa, regangan sebesar $27.5 \%$, dan modulus elastisitas sebesar $3.73 \mathrm{GPa}$.

Dari hasil pengujian tarik yang dilakukan didapatkan grafik perbandingan tegangan dan regangan pada gambar 8 . 


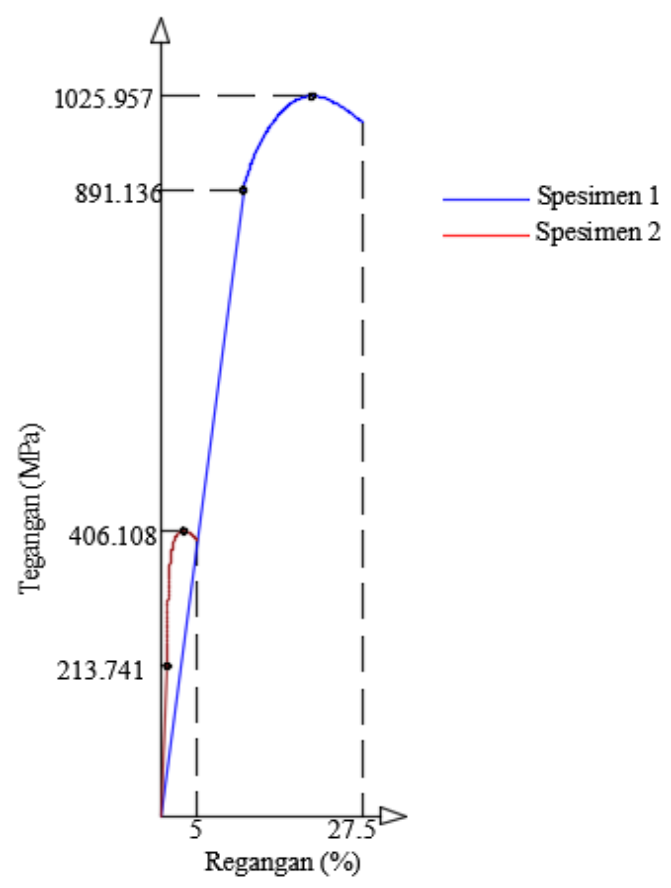

Gambar 8. Grafik hubungan tegangan dan regangan

(Sumber : Data primer)

Proses penyambungan monel dengan pengelasan gesek belum layak untuk digunakan kembali, karena kekuatan tariknya yang kurang dari setengah dari kekuatan tarik logam monel raw metal tanpa pengelasan. Penyambungan logam monel menggunakan pengelasan gesek perlu penelitian lebih lanjut agar hasil dari las gesek bisa dimaksimalkan dengan variasi waktu pengelasan gesek, variasi beban gesek dan penambahan beban tempa.

\section{KESIMPULAN}

Berdasarkan hasil pengujian diperoleh kesimpulan dari penelitian ini adalah sebagai berikut:

1. Tegangan tarik maksimal pada spesimen 2 hasil pengelasan gesek logam similar monel yaitu sebesar 406.108 Mpa, regangan sebesar $5.0 \%$, dan modulus elastisitas sebesar 8.12 gpa. Sedangkan kekuatan tarik maksimal spesimen 1 monel tanpa pengelasan gesek yaitu sebesar 1 $025.957 \mathrm{MPa}$, regangan sebesar $27.5 \%$, dan modulus elastisitas sebesar $3.73 \mathrm{GPa}$.
2. Proses penyambungan monel dengan pengelasan gesek belum layak untuk digunakan kembali, karena kekuatan tariknya yang kurang dari setengah dari kekuatan tarik logam monel raw metal tanpa pengelasan.

\section{REFERENSI}

[1] A. Sastranegara. Mengenal Uji Tarik dan Sifat-sifat Mekanik Logam. Situs Informasi Mekanika, Material, dan manufaktur, 8 (2009).

[2] Mulyadi. Pengaruh Model Speciment Uji Tarik Pada Pengelasan Besi Fc-30 Di Lihat Dari Kekuatan Tarik Pengelasan. Rekayasa Energi Manufaktur, 1(2), (2016) 29-36.

[3] AWS. Welding Handbook. A. O'Brien \& G. Carlos, Eds. 9th ed., Vol. 3. Miami (2007).

[4] M. Iswar \& R. Syam. Pengaruh Variasi Parameter Pengelasan (Putaran dan Temperatur) Terhadap Kekuatan Sambungan Las Hasil Friction Welding Pada Baja Karbon Rendah. Jurnal Mekanikal 10 (2012): 254-260.

[5] F.Irwanto, Pengaruh Tekanan Gesek 1, 38-4, 14 Mpa Terhadap Waktu Lebur Dan Pengaruh Tekanan Tempa 6, 90-8, 27 Mpa Terhadap Kekuatan Tarik Pada Pengelasan Gesek Dengan Bahan Stainless Steel 304 (Doctoral dissertation, FT UMY). (2013).

[6] M.Suratman, Teknik Mengelas. Cetakan I, Pustaka Grafika, Bandung, 2001.

[7] L. Bates, R. Brown, Laboratory Uses of Monel Metal. Nature 122, 240 (1928)

[8] L. E. Shoemaker\& G. D. Smith, A century of monel metal: 1906-2006. JOM, 58(9), (2006) pp. 22-26 